\title{
Floods in Tabasco Mexico: history and perspectives
}

\author{
L. Gama ${ }^{1}$, E. M. Ordoñez ${ }^{1}$, C. Villanueva-García ${ }^{1}$, \\ M. Arturo Ortiz-Pérez ${ }^{2}$, H. D. Lopez ${ }^{1}$, R. C. Torres ${ }^{1}$ \\ \& M. E. M. Valadez ${ }^{1}$ \\ ${ }^{1}$ Division Academica de Ciencias Biologicas, \\ Universidad Juarez Autonoma de Tabasco, Mexico \\ ${ }^{2}$ Universidad Nacional Autonoma de Mexico, Mexico
}

\begin{abstract}
Tabasco is located in one of the ten more important basins of North America. One third of all water resources in Mexico passes through here. Flooding events are part of the natural history of the basin; however floods have increased spatially and in magnitude. Data regarding total annual rainfalls as high as $4000 \mathrm{~mm}$ are registered regularly within the border of Tabasco and Chiapas. The most important wetlands of Mexico are located here on the low river basin of the Grijalva and Usumacinta rivers. Since ancient times, people in this part of Mexico are related to this flooding system in a variety of ways. A system of dams generates most of the electricity power used on Southern Mexico. Oil exploitation, cattle breeding and agriculture are the main economic activities and are responsible for an important loss of the natural ecosystems and ecosystem services. The objective of this research was to study flooding causes in this area. Geomorphology, climate, topography, hydrology and soil maps were constructed. A historical review of floods, river courses, and land use as well as an analysis of meteorological data were performed. Ecosystem vulnerability was evaluated. Results show that there has been a loss of $90 \%$ of the original biodiversity of tropical forest due mainly to farming and poor cattle management activities. Road infrastructure, unplanned urban growth and oil exploitation infrastructure has caused an important impact especially on the hydrodynamics and coastal areas. Extraordinary events with more than $200 \mathrm{~mm}$ in 24 hours are more common each year. The amount and intensity of floods today has increased and put at risk a great number of the population. Climate change
\end{abstract}


would increase the possibility of floods. Results propose conservation policies to protect or recover ecosystem services.

Keywords: Mexico, floods, climate change, dams, wetlands, extreme precipitation, rivers.

\section{Introduction}

Climate variability differs in scales of time and space. However, the phenomena of variability such as the "Southern Oscillation" known as "El Niño" affects large regions and leaves, among other effects, strong drought years followed by seasons with severe thunderstorms. To understand local variability related to these events, further studies must be carried out. Different impacts are expected due to climate change and Mexico is vulnerable to all of them in various degrees and areas. The scenarios predict different degrees of changes related mainly to the increases in temperature and changes of precipitation distribution. Although there is still no clarity regarding the behavior of rains for Mexico, there would mainly be a decrease according to the scenery predictions in most of the country that would carry important water stress conditions affecting the vegetation cover and agricultural activities although in Southern Mexico this decrease would not reflect clearly dry conditions.

The warm and humid tropical climate such as the one in Southern Mexico have already shown some "signs" of climate change, such as the "increase" of some extreme precipitation events, despite the potential decrease in precipitation expected according to the global generated scenarios. Tabasco, due to its geographical location, is characterized by special physiographic and geomorphologic features that yearly expose this territory to mild floods. Several effects are expected to occur related to climate change in the State. An example of these extraordinary precipitation events is that in less than a decade, there have been three important flood events related to intense winter rainfall with an extension of almost $70 \%$ just for the flood of 2007 .

As mentioned, floods are related to extreme precipitation events. However, sea level elevation is also a possible threat to a very dynamic coast line due to the subsidence phenomena; vulnerability studies and predictions made by scientists related to glaciers melting increase this threat (1). The change in the planet average temperature will also be the cause of floods in coastal regions like Tabasco that is already suffering floods associated with extreme rain events (2).

According to the records of the last 100 years, there has been an important increase in the temperature of the planet related to greenhouse gases. In fact, the last decade has been the warmest in recent centuries. As the temperature rises, there is a thermal expansion of water, and low areas in Tabasco are highly vulnerable (there are important extensions with less than a meter above sea level). There are extreme projections about the consequences of this change at sea level that have changed as there is more available information (HernandezSantana et al. [1], Ortiz-Perez [3]). These facts, coupled with changes in precipitation patterns, make most of Tabasco territory vulnerable to higher and more intense floods. 
Historical studies of the changes that the basin and the hydrology of the territory have undergone are important to understand and find out the relationship between the recent increases in the intensity, extension and magnitude of yearly floods.

Vulnerability studies to these threats are needed in order to design strategies to protect the population. The data collected give support for a diagnostic in relation to the different impacts expected by global climate change. These results, and the ones from other researchers and other environmental planning tools, will allow local government decision makers to have feasible data to establish development strategies taking into consideration areas with high risk.

In relation to extreme events in Tabasco, most of the territory was affected in late October 2007, where large areas of the State and some villages of Chiapas were flooded with unprecedented magnitude and duration. The volume of precipitation fallen during the days of this episode over passed $600 \mathrm{~mm}$ in three days, more than $400 \mathrm{~mm}$ occurred in just one day (on 28 October, 2007). This $600 \mathrm{~mm}$ represents the common total rain fall for a rainy month as has been previously documented by the National Weather Service. Historical records of previous decades had documented cases of rainfall in 24 hours with values above $300 \mathrm{~mm}$ in the region. The trend of recent years indicates that these cases are increasing, and that the maximum annual precipitation can be considered even greater.

Since ancient times, the Mayan culture developed several systems to manage natural resources in this area. Most of their activities and techniques were developed taking into account conservation practices. Their home gardens were rich in useful trees, which provided with food, fiber, firewood and material for construction. The continuous anthropogenic incidence on these systems resulted in different kinds of managed forest and orchards that even today can be found.

Because of its climatic and biologic characteristics, this region has the most important wetland area of the country "Centla Swamps" a Biosphere reserve. Although forest exploitation has been high, the lack of communication possibilities was a control to this activity. Until the middle of the last century, agricultural and cattle raising activities in Tabasco had depended on annual flooding periods. As the basin where Tabasco is located has two of the most important rivers in Mexico, a series of four huge hydroelectric dams were built. These dams were expected to help as flood control and for irrigation systems for agricultural and cattle growing activities that increased as well as urban centers especially in non flooding areas. Important areas were developed to grow sugar cane, banana and rice.

The state of Tabasco is important for the oil industry, the main activity performed in the gulf coast of Mexico. This exploitation started at the beginning of 1970, with huge amounts of infrastructure associated to it including areas to help the transportation of oil to other parts of Mexico and outside of the country like the "Frontera" port. Today, important environmental impacts associated to this industry can be found in all the State especially in coastal areas.

Furthermore, rates of poverty and marginalization in this region are significant, population growth with little potential for development, coupled with 
a messy urban growth, causes large numbers of people to be exposed to the risk of extraordinary hydro-meteorological events. This part of the country, rich in natural resources and ethnic groups, is the least developed area regarding policies to enhance development for generating a better quality of life. Besides, the southern region of Mexico has the highest deforestation rate in the country, which is the cause of an increase in runoff and reduction in the infiltration of rainwater. Deforestation also leads to an increase in soil erosion, an increase in sediment transport that causes a decrease in riverbeds, reducing their capacity to transport large volumes of water, thereby allowing more frequent floods. Therefore, the analysis of the historical causes of the potential threats already suffered in Tabasco is essential in order to understand the root that causes them be magnified by climate change so as to be able to propose measurements against the vulnerability to which thousands of people are exposed today in the State and would be in the near future.

\section{Methodology}

In order to understand the increase in frequency and magnitude of floods to determine the vulnerability, research was carried out to find out where the population was at risk. Four aspects were basically addressed: 1) A historical analysis and changes regarding rainfall based on bibliographic data and recorded data relating to floods as well as reported damages; 2) An analysis of changes in soil use, coast line variation and natural or human modifications of superficial hydrology; 3) A review of climate change scenarios and their possible effect in the future of the region; and 4) The development of a vulnerability map for the State considering these elements.

The analysis of the impacts of extreme rainfall events and possible floods relating to sea level increase required interdisciplinary teams that involve three institutions. A diagram of the methodology is shown in figure 1.

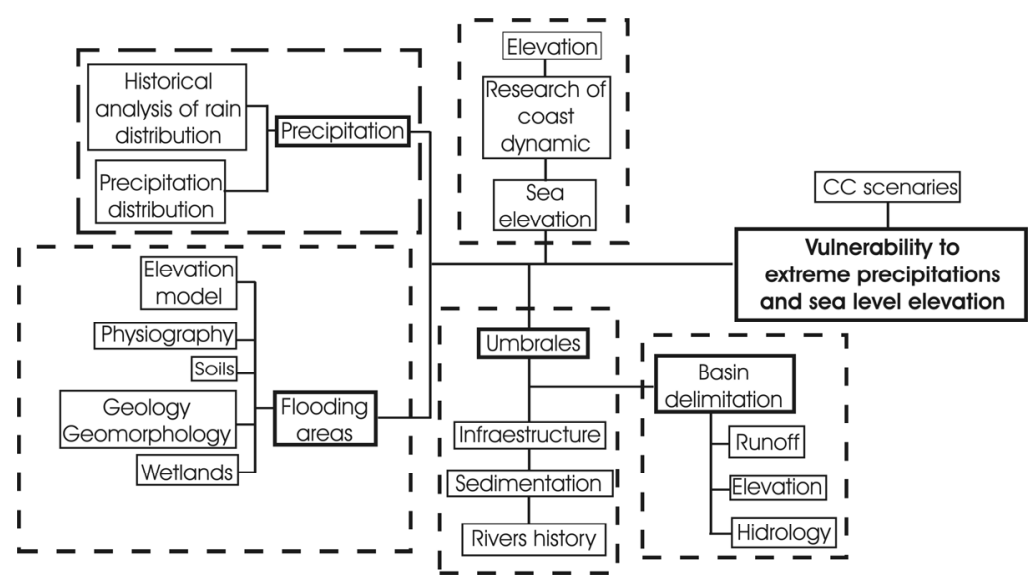

Figure 1: Methodology diagram. 
A review of the available sources of historical information related to floods in the region and extreme rainfall events from the National Historical File that saves information from reports of floods as well as photographs (photographs as old as 1921 from the center of Villahermosa were found) among others was made. The information was recorded on a data base and geographical coordinates were added for geographical reference.

Meteorological data regarding temperature and precipitation variables from different sources and official institutions like CONAGUA (National Commission of Water) were recorded and saved on a data base for statistical, graphic and cartographic analysis and models.

All data regarding damage was recorded as well as the information relating to measures taken into account each time in order to avoid future floods. Data relating to the infrastructure constructed after each event to control future floods or coast damages as well as costs associated with the damage was also recorded.

Precipitation data from the Global Historical Climatology Network (GHCN) in addition to Mexican data from the Mexican National Water Commission were assembled from 387 stations in southern Mexico (data from historical and actual records from 90 stations in Tabasco and 297 in Chiapas). Monthly precipitation data were converted to the Standardized Precipitation Index and interpolated to generate monthly contour maps of the area to model precipitation distribution in the region to determine possible variations.

All maps [4] found where digitized including historical diagrams dated as far back as the XVI century. Aerial photos and historical data were reviewed to evaluate changes of the hydrological system. Measured were taken to compare changes in the coast line to find out impacts related to possible sea level elevation.

Climate change scenarios developed for Mexico for the National Climate Communications constructed for the United Nation Framework Convention on Climate Change (COP15 United Nations Climate Change Conference, 7-18 December, 2009) were used to estimate future impacts related to rainfall variability.

An analysis was performed to evaluate vulnerability related to floods due to the characteristics of the basin (physiography, geomorphology, hydrology, soil, vegetation and soil uses, infrastructure, roads), and the increase in precipitations. As a result of the evaluation a vulnerability map was constructed to relate to the population at risk.

\section{Results}

Tabasco has undergone important land cover changes due mainly to agricultural, and cattle raising activities. Important activities related to oil extraction are also affecting natural landscapes. The hydrodynamic of the basin has been severely altered due to infrastructure growth and urbanization. Historical reviews show that some of the infrastructure constructed to protect urban areas against floods had not been supported with studies relating to the impacts associated with the natural components of the area. 


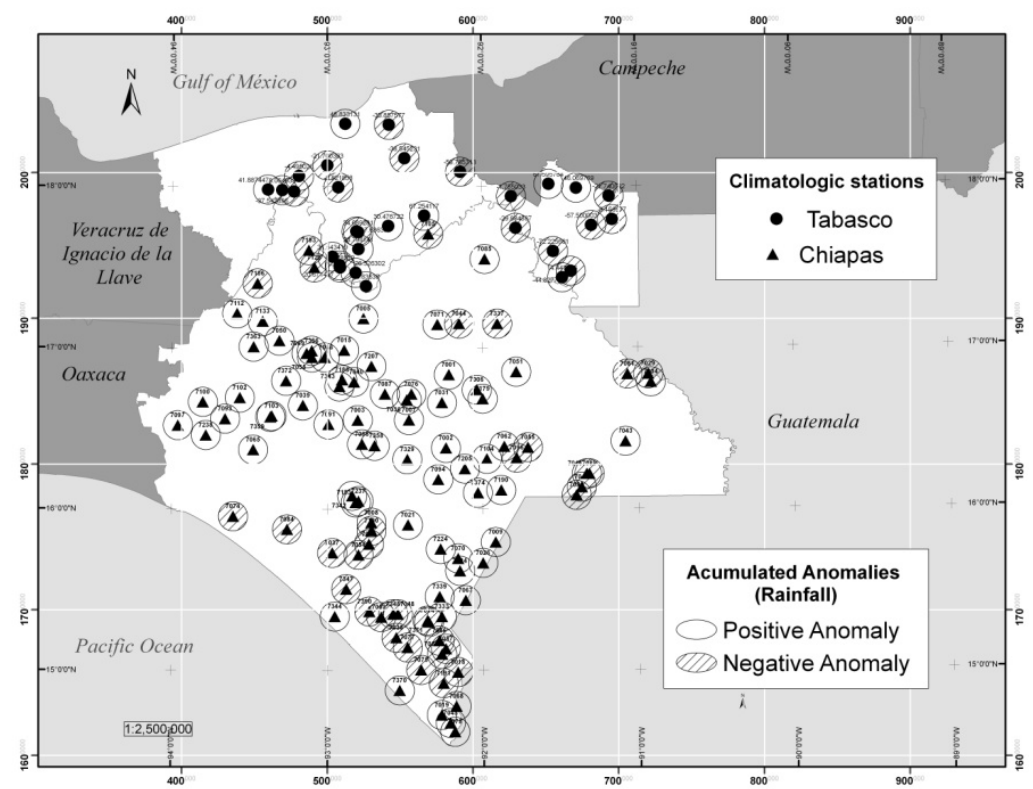

Figure 2: Map of the states of Tabasco and Chiapas showing positive and negative anomalies on rain falls.

Tabasco has today 43 meteorological active stations in its territory with data that range from 5 to 52 years, the oldest one being from 1949. A total of sixteen stations were selected for the analysis among those that had at least a period of 30 years of continuous data that were validated. An analysis of the daily precipitation data per meteorological station was performed to find out anomalies (figure 2) in the amount of rainfalls and the frequency of extreme events (example in figure 3). Changes in precipitation patterns are more frequent according to the data.

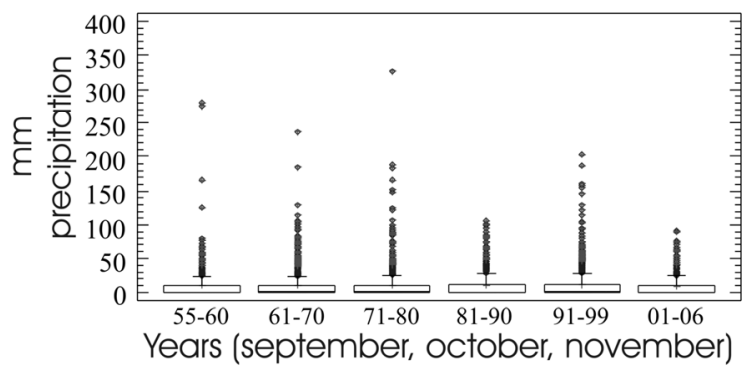

Figure 3: Data of daily precipitation of the Cunduacan station for the months of September to November, the rainy season of the year. 
A review of the rainfall data showed that in Chiapas June, July, August and September are the months with higher rainfalls, while for Tabasco, June, August, September and October are related to strong thunder storms associated with floods. Graphs of the daily rain with historical precipitations data were constructed for these months to find out if there was a return time for floods (figures 4 Villahermosa floods registered). Although, unplanned urban growth is one of the most important reasons for floods as constructions had been developed of swamps and natural flooding areas as can be seen in figure 5 .

A comparison of the measurements taken over long time periods on the coast show that there are some areas where there are important losses of more than ten meters of coast line per year due to subsidence effect and a very dynamic tide action (figure 6). Climate change.

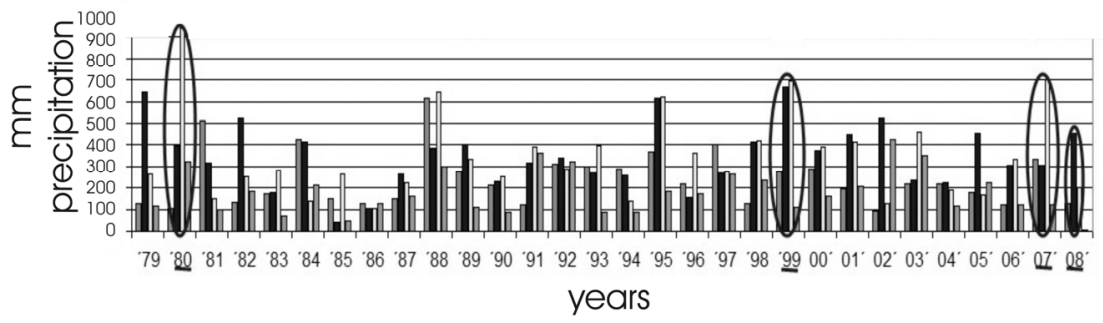

Figure 4: Rainfall in 24 hours register that exceeds the normal for July, August, September and November for 1979 to 2008, to important floods registered 2007, 2008, no return period.

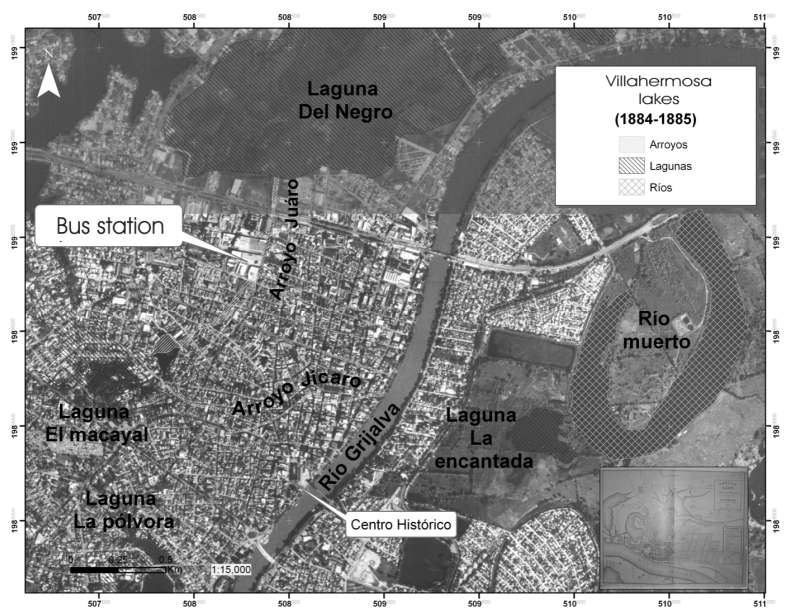

Figure 5: Urban growth on natural flooding areas in the city of Villahermosa, capital of the State with half a million inhabitants. 


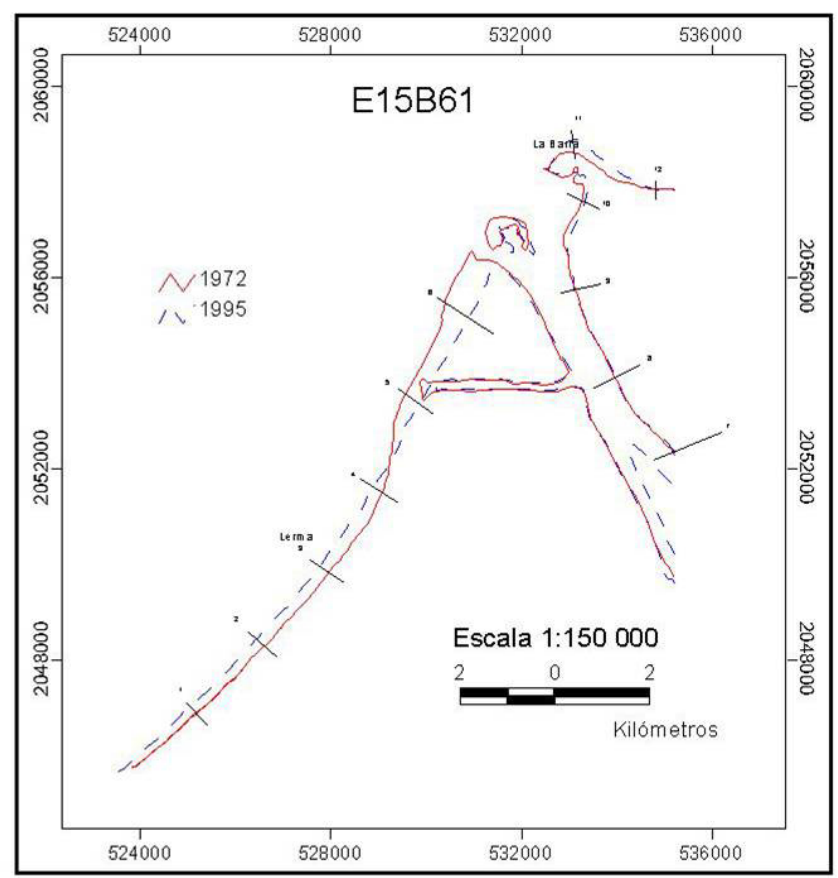

Figure 6: Delta of the Usumacinta River with important changes in coast line.

According to research results presented by different international groups at the Climate Change Intergovernmental Panel, under the best future scenarios, due to ice melting, there is a possibility of a sea level rise of about 60 centimeters by the end of this century related to climate warming.

Due to the fact that Tabasco is mainly located on a flat natural flooding region, where subsidence events are occurring on the territory, related in many cases to oil exploitation, any sea level registered would put at risk the population living by the coast line or close to it. Many impacts are already going on related to the strong dynamic change undergoing now where important areas would suffer, among other things, sea water intrusions and changes in fauna distribution.

\section{Discussion}

Tabasco is already suffering impacts resulting from modifications in rainfall distribution due to changes in the variability of precipitation that would probably increase because of climate change. Monitoring stations, studies relating to vulnerability as well as adaptation strategies are required to be able to minimize population risk in the future.

The last decades' floods had increase in magnitude, extension and intensity. Yearly floods of about half a meter, nowadays could be as high as four meters. 
At the end of the fall season, winter rains collide with tropical events and a great amount of rain falls in the territory. Due to the fact that the soil does not have good drainage, floods are more common. However, and unplanned growth and hydraulic infrastructure constructed to prevent floods that do not take into account the natural hydrology of the territory increases the risk of damages related to them.

A vulnerability map was constructed to locate populations at risk, however results and recent flood events show that more than half of the population could be living in high risk areas.

There is a need for plans that take vulnerability into account and for authorities to implement strategies of mitigation and adaptation taking into account these variables.

These strategies would help update the territorial planning for future scenarios with alternatives for the economic activities performed, human localities, natural ecosystem conservation and possible alternative species refuges.

\section{References}

[1] Hernández Santana, J. R., M. A. Ortiz Pérez, A. P. Méndez Linares and L. Gama Campillo. 2008. Morfodinámica de la línea de costa del estado de Tabasco, México: tendencias desde la segunda mitad del siglo XX hasta el presente. Investigaciones Geográficas, Boletín del Instituto de Geografía. UNAM. 65:7-21.

[2] Tejeda A. Martínez, A. and L. Rodríguez-Viqueira. 2007. Estado de la investigación de los aspectos físicos del cambio climático en México. Investigaciones Geográficas, Boletín del Instituto de Geografía, UNAM, núm. 62: 31-43.

[3] Ortiz-Pérez, M. A. 1994. Repercusiones del ascenso del nivel del mar en el litoral el Golfo de México: un enfoque geográfico de los problemas del cambio global. México ante el Cambio Climático, Memorias del Primer Taller de Estudio de País: México, Cuernavaca, Morelos, pp. 191-197.

[4] Gobierno del Estado. 1982. Atlas historico de Tabasco 1570-1981. Consejo editorial del Gobierno del estado de Tabasco. Mexico. 208 pp. Impreso en los Talleres de Edimex S.A 